\title{
Cognitive and Language Function in Aphasic Patients Assessed With the Korean Version of Mini-Mental Status Examination
}

\author{
Eun Kyoung Kang, MD, PhD ${ }^{1}$, Hyun Sun Jeong, SLP ${ }^{2}$, Eun Rhan Moon, SLP², \\ Joo Young Lee, $\mathrm{MD}^{2}$, Kun Jai Lee, $\mathrm{MD}^{1,3}$
}

\begin{abstract}
${ }^{1}$ Department of Rehabilitation Medicine, Kangwon National University Hospital, Chuncheon; ${ }^{2}$ Department of Rehabilitation Medicine, Seoul Bukbu Hospital, Seoul; ${ }^{3}$ Department of Rehabilitation Medicine, Kangwon National University

College of Medicine, Chuncheon, Korea
\end{abstract}

Objective To assess the clinical usefulness of the relatively short instrument, the Korean version of the MiniMental State Examination (MMSE-K), for testing the association between cognition and language function in subacute post-stroke aphasia patients.

Methods Medical charts of 111 post-stroke patients (65 men; age $69.6 \pm 10.0$ years; $124.6 \pm 80.6$ days post-onset) were reviewed retrospectively. All patients were assessed longitudinally for aphasia using the validated Korean version of the Western Aphasia Battery (K-WAB) and for cognition using the MMSE-K. Patients were categorized and analyzed according to 3 aphasia-severity clusters.

Results All subscales of the K-WAB showed significant improvement in follow-up assessments in all groups $(\mathrm{p}<0.05$ or $\mathrm{p}<0.01$ ). Only the scores of orientation, language function, and total score of MMSE-K showed significant improvement in all groups $(\mathrm{p}<0.01)$. The more severely impaired group showed stronger Pearson correlation coefficients between cognition and language function. Additionally, comparisons between correlation coefficients showed that the association of improvement in orientation with that of fluency and AQ\% (aphasia quotient \%) was significant in the more severely impaired group.

Conclusion Among subacute post-stroke aphasic patients, patients with more severe aphasia showed greater impairments to cognitive function; in addition, recovery of orientation may be related to recovery of language function.

Keywords Stroke, Aphasia, Cognition, Language, Orientation

\footnotetext{
Received June 29, 2015; Accepted August 12, 2015

Corresponding author: Kun Jai Lee

Department of Rehabilitation Medicine, Kangwon National University Hospital, Kangwon National University College of Medicine, 156 Baengnyeongro, Chuncheon 24289, Korea

Tel: +82-33-258-9100, Fax: +82-33-258-2146, E-mail: kjleerh@kangwon.ac.kr
}

(c) This is an open-access article distributed under the terms of the Creative Commons Attribution Non-Commercial License (http://creativecommons.org/ licenses/by-nc/4.0) which permits unrestricted noncommercial use, distribution, and reproduction in any medium, provided the original work is properly cited. Copyright $\odot 2016$ by Korean Academy of Rehabilitation Medicine 


\section{INTRODUCTION}

Stroke is a disabling chronic condition including motor weakness, dysphagia, cognitive decline, language disorders, and mood disorders, resulting in serious decrements to mobility, activities of daily living, nutrition, communication, and quality of life [1-3]. In particular, recent research has focused on the relationship between cognition and language after stroke [4-7], because the boundaries of these affected areas are unclear and may overlap [8]. Furthermore, stroke is also associated with concomitant morbidities in memory, orientation, language, and attention [9].

Several studies have focused on the cognitive impacts of language function in post-stroke aphasic patients. In a non-linguistic cognitive examination including abstract reasoning, visual memory, visual perception and construction, and executive functioning, El Hachioui et al. [4] reported that non-linguistic cognitive impairments are common and associated with poor functional outcomes and depression, especially in patients with persisting aphasia. Moreover, Lee and Pyun [6] used computerized neurocognitive functional batteries to assess attention, executive function, and intelligence and reported significantly impaired working memory and sustained attention in aphasic patients and significant correlations between cognitive deficits and aphasia severity in only some tests of attention. Yu et al. [5] used the Loewenstein Occupational Therapy Cognitive Assessment (LOTCA) battery, which is a performance test with minimal verbal requirements except for orientation and is suitable for testing cognitive function in post-stroke patients with language dysfunction, and showed a close relationship between linguistic functions and cognitive orientation, spatial perception, visual perception, and thinking operation [10].

Previous studies, however, have adopted neuropsychological tests which are difficult to apply because they require specialists such as clinical psychologists and long durations of testing. These studies have also not considered aphasia severity, which affects the clinical course of recovery $[11,12]$. Moreover, most neuropsychological tests that have been used require both linguistic and nonlinguistic cognitive domains in their test instructions and performance procedures. Raven's progressive colored matrices [13], which is easily obtained and can be ad- ministered to most individuals with aphasia independent of their language deficits, mainly targets only visual analogical thinking [14].

If a clear distinction between cognition and language function is possible, popular and easy to adopt neuropsychological tests that assess the impact of cognition on language or vice versa should be utilized for indication of recovery or prognosis in post-stroke aphasia patients. The Korean version of the Mini-Mental State Examination (MMSE-K) has become a widely used cognitive screening tool due to its brevity and straightforward administration [15-17] and is usually included in assessments of poststroke patients in clinical and research settings. Thus, we aimed to identify the clinical usefulness of MMSE-K for assessing the association between cognition and language function in subacute post-stroke aphasia patients.

\section{MATERIALS AND METHODS}

\section{Participants}

The current study used a sample of first-ever poststroke aphasic patients within 12 months of onset who were admitted to speech therapy units within a rehabilitation hospital from March 2009 to July 2013. Patients were excluded if: 1) they were not classified into a specific aphasia type, 2) onset was over a year prior to assessments, or 3) language disturbances occurred following conditions that were not related to stroke, such as traumatic brain injury, neurodegenerative disease, or brain tumors. Patients were categorized into 3 aphasiacluster groups based on aphasia severity. This study was approved by the Institutional Review Boards at Kangwon National University Hospital including the retrospective review of the patients' medical records (IRB No. 2013-08007-001).

\section{Measurements}

All patients were assessed longitudinally for aphasia and cognition at immediately after admission and at 3 months following admission. They were assessed for aphasia using a validated Korean version of the Western Aphasia Battery (K-WAB) [18]. Two trained speech-language pathologists (SLPs) administered the K-WAB with the same evaluation protocol. The K-WAB consists of 4 domains: fluency (range: 0-20), comprehension (0-200), repetition (0-100), and naming (0-100). For determin- 
ing the severity of aphasia, the AQ\% (aphasia quotient \%; range, 0-100) was calculated using the following formula: (fluency score+[comprehension score/20]+[repetition score/10]+[naming score/10]) $\times 2$ [19]. Scores in these domains were used for the classification of aphasia subtypes according to Kertesz's method [20].

Cognition among patients was assessed using the MMSE-K [16]. The MMSE-K (total score range, 0-30) for the assessment of cognitive performance was administered by 2 trained occupational therapists with the same evaluation protocol. The battery includes 6 cognitive domains: orientation (range, $0-10$ ), memory registration $(0-3)$, concentration and calculation (0-5), memory recall (0-3), language function (0-7), and comprehension and judgment (0-2) [21,22]. Compared to the MMSE, the MMSE-K includes 'comprehension and judgment' as additional subscores instead of being included under 'language function' as in the original version of MMSE [23].

We also collected descriptive information regarding patients' age, sex, duration of formal education (years), dominant hand (left, right, or both), post-onset days, etiology of stroke (infarction or hemorrhage), and existing brain lesions. Hand dominance was determined by examining the hand that patients typically used for writing, feeding, throwing, using scissors, and cutting while using knives. Left- versus right-handedness was indicated by a preference for a particular hand in $>3$ of the 5 items modified from the Edinburgh Handedness Inventory [24]. Lesions resulting from strokes were identified after reviewing patients' brain computed tomography (CT) or magnetic resonance imaging (MRI) scan reports.

\section{Statistics}

Statistical analyses were performed using SPSS for Windows ver. 20.0 (IBM, Armonk, NY, USA). First, to categorize patients by aphasia severity, two-step cluster analysis (pre-clustering into the many small sub-clusters and then clustering these sub-clusters into the desired number of clusters) was conducted using AQ\% scores and Schwarz's Bayesian criteria. This method automatically selects the number of clusters [25]. Descriptive statistics were obtained for demographic variables and measurements according to cluster classification. Second, we compared scores of the K-WAB and MMSE-K at baseline and at 3 months following admission by conducting paired t-tests. The mean differences between the 2 time-point scores were obtained. Third, Pearson correlation coefficients were calculated to evaluate the association between differences of subscores of the K-WAB and MMSE-K. Comparisons between Pearson correlation coefficients were performed using an on-line calculator for the differences between 2 independent correlation coefficients (http:// www.quantpsy.org/corrtest/corrtest.htm) [26]: first, each correlation coefficient is converted into a z-score using Fisher r-to-z transformation, then making use of the sample size employed to obtain each coefficient, these zscores are compared using formula 2.8.5 from Cohen et al. [27]. By convention, z-scores $>|1.96|$ were considered significant for two-tailed tests. Data were presented as mean \pm standard deviation.

\section{RESULTS}

The medical charts of 111 post-stroke patients ( 65 men and 46 women; average age $69.6 \pm 10.0$ years; $124.6 \pm 80.6$ days post-onset) were reviewed retrospectively. All patients were right-handed and reported left-side brain lesions. After cluster analysis based on AQ\%, we obtained the 3 groups of aphasia cluster: group I-anomic ( $n=9)$, conduction $(n=1)$, mixed transcortical $(n=4)$, transcortical motor $(\mathrm{n}=4)$, transcortical sensory $(\mathrm{n}=1)$, Wernicke $(\mathrm{n}=9)$; group II, Broca's aphasia $(\mathrm{n}=31)$; and group III, global aphasia $(n=52)$ in terms of aphasia type. One-way ANOVA showed greater mean age of group III, as compared to group II $(71.8 \pm 10.1$ versus $65.9 \pm 9.5 ; \mathrm{p}=0.02$ in a Tukey post-hoc test). Education duration and post-onset days were not significantly different. Ischemic stroke was more frequent than hemorrhage stroke in all groups $\left(\chi^{2}=6.3, \mathrm{df}=2, \mathrm{p}=0.04\right)$, while neither categorical age $(<65$ vs. $\geq 65$ years), post-onset duration ( $<6$ months vs. $6-12$ months), nor sex were statistically different between groups. Cortical brain lesions were more frequent than subcortical lesions in all aphasia-cluster groups $\left(\chi^{2}=8.2\right.$, $\mathrm{df}=2, \mathrm{p}=0.02$ ) (Table 1 ).

Table 2 showed the differences in K-WAB and MMSE-K between the initial and follow-up assessments. All subscales of K-WAB were significantly improved during follow-up assessments in all aphasia cluster groups $(\mathrm{p}<0.05$ or $\mathrm{p}<0.01)$. For the MMSE-K, only the scores of orientation, language function, and total score were significantly improved in all groups $(\mathrm{p}<0.01)$. Concentration and calculation and comprehension and judgment scores were 
Table 1. Baseline characteristics according to the aphasia cluster

\begin{tabular}{|c|c|c|c|c|}
\hline Variable & Group I $(n=28)$ & Group II (n=31) & Group III $(n=52)$ & Overall $(n=111)$ \\
\hline Age $(y r)^{a)}$ & $69.3 \pm 9.7$ & $65.9 \pm 9.5$ & $71.8 \pm 10.1$ & $69.6 \pm 10.0$ \\
\hline$<65$ & $6(5.4)$ & $13(11.7)$ & $12(10.8)$ & $31(27.9)$ \\
\hline$\geq 65$ & $22(19.8)$ & $18(16.2)$ & $40(36.0)$ & $80(72.1)$ \\
\hline \multicolumn{5}{|l|}{ Sex } \\
\hline Men & $16(14.4)$ & $19(17.1)$ & $30(27.0)$ & $65(58.6)$ \\
\hline Women & $12(10.8)$ & $12(10.8)$ & $22(19.8)$ & $46(41.4)$ \\
\hline Educational duration (yr) & $10.5 \pm 4.4$ & $8.9 \pm 6.1$ & $8.8 \pm 5.1$ & $9.3 \pm 5.2$ \\
\hline Handedness, all right & $28(25.2)$ & $31(27.9)$ & $52(46.8)$ & $111(100)$ \\
\hline Post-onset days & $120.6 \pm 87.6$ & $116.6 \pm 78.9$ & $131.5 \pm 78.7$ & $124.6 \pm 80.6$ \\
\hline$<6 \mathrm{mo}$ & $22(19.8)$ & $28(25.2)$ & $37(33.3)$ & $87(78.4)$ \\
\hline 6-12 mo & $6(5.4)$ & $3(2.7)$ & $15(13.5)$ & $24(21.6)$ \\
\hline \multicolumn{5}{|l|}{ Type of stroke $e^{\text {b) }}$} \\
\hline Infarction & $17(15.3)$ & $19(17.1)$ & $43(38.7)$ & $79(71.2)$ \\
\hline Hemorrhage & $11(9.9)$ & $12(10.8)$ & $9(8.1)$ & $32(28.8)$ \\
\hline \multicolumn{5}{|l|}{ Brain lesion, all left side ${ }^{\mathrm{c})}$} \\
\hline Cortical lesion & $18(16.2)$ & $23(20.7)$ & $47(42.3)$ & $88(79.3)$ \\
\hline MCA territory & $15(13.5)$ & $20(18.0)$ & $44(39.6)$ & $79(71.2)$ \\
\hline ACA territory & $0(0.0)$ & $1(0.9)$ & $0(0.0)$ & $1(0.9)$ \\
\hline MCA+ACA territory & $3(2.7)$ & $2(1.8)$ & $3(2.7)$ & $8(7.2)$ \\
\hline Subcortical lesion & $10(9.0)$ & $8(7.2)$ & $5(4.5)$ & $23(20.7)$ \\
\hline Basal ganglia & $8(7.2)$ & $6(5.4)$ & $4(3.6)$ & $18(16.2)$ \\
\hline Thalamus & $1(0.9)$ & $1(0.9)$ & $0(0.0)$ & $2(1.8)$ \\
\hline Basal ganglia+thalamus & $1(0.9)$ & $1(0.9)$ & $1(0.9)$ & $3(2.7)$ \\
\hline \multicolumn{5}{|l|}{ Discharge destination } \\
\hline Home & $13(11.7)$ & $13(11.7)$ & $10(9.0)$ & $36(32.4)$ \\
\hline Other facility & $15(13.5)$ & $18(16.2)$ & $42(37.8)$ & $75(67.6)$ \\
\hline Aphasia cluster & $\begin{array}{l}\text { Anomic (9), } \\
\text { conduction (1), } \\
\text { mixed transcortical (4), } \\
\text { transcortical motor (4), } \\
\text { transcortical sensory (1), } \\
\text { Wernicke (9) }\end{array}$ & Broca (31) & Global (52) & \\
\hline \multicolumn{5}{|l|}{ Functional level $^{\text {d) }}$} \\
\hline BBT (initial) & $23.9 \pm 17.5$ & $26.4 \pm 15.9$ & $13.3 \pm 15.4$ & $19.5 \pm 17.0$ \\
\hline BBT (follow-up) & $34.8 \pm 16.0$ & $34.8 \pm 17.2$ & $18.9 \pm 17.5$ & $27.4 \pm 18.6$ \\
\hline K-MBI (initial) & $43.0 \pm 23.4$ & $49.3 \pm 23.5$ & $26.7 \pm 24.6$ & $37.1 \pm 25.8$ \\
\hline K-MBI (follow-up) & $56.2 \pm 23.0$ & $59.0 \pm 20.0$ & $36.6 \pm 28.4$ & $47.7 \pm 27.0$ \\
\hline
\end{tabular}

Values are presented as mean \pm standard deviation or number $(\%)$
$\mathrm{n}$, sample size; MCA, middle cerebral artery; ACA, anterior cerebral artery; BBT, Berg Balance Test; K-MBI, Korean version of Modified Barthel Index.

${ }^{a)} \mathrm{p}=0.02$ between group II and III by one-way ANOVA followed by Tukey post-hoc test. Educational duration and postonset days were not significantly different among the groups.

${ }^{b)} \mathrm{p}=0.04$ by chi-square analysis $\left(\chi^{2}=6.3\right)$. Categorical age ( $<65$ vs. $\geq 65$ years $)$ and post-onset duration $(<6$ mo vs. $6-12$ mo) and sex did not show statistical significances.

${ }_{c} p=0.02$ by chi-square analysis $\left(\chi^{2}=8.2\right)$ between aphasia clusters and brain lesions (cortical vs. subcortical lesion).

${ }^{d)}$ Group III showed significantly low functional level, as compared to group I or II by one-way ANOVA followed by Tukey post-hoc test $(\mathrm{p}<0.05, \mathrm{p}<0.01$ or $\mathrm{p}<0.001)$. 


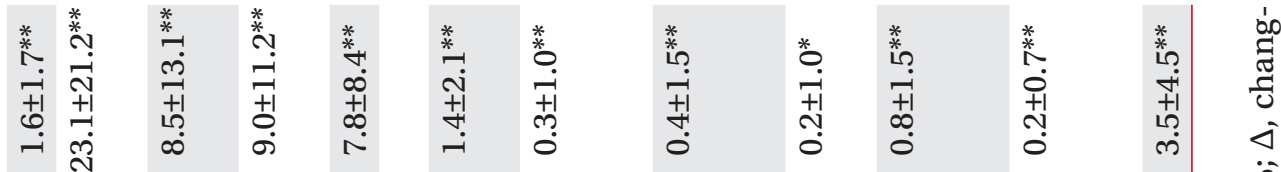

둥

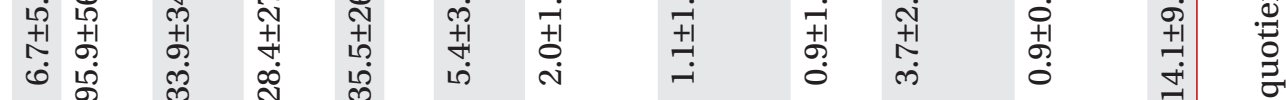

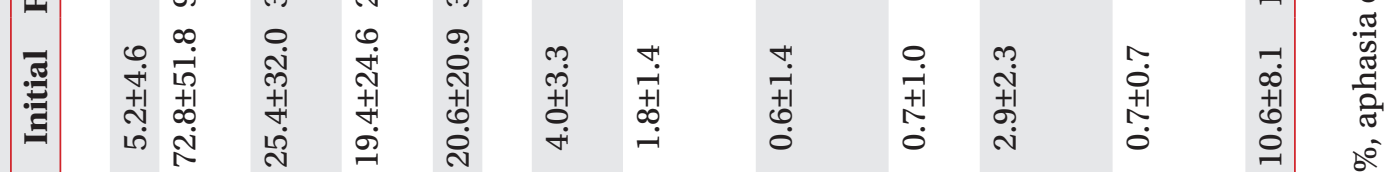

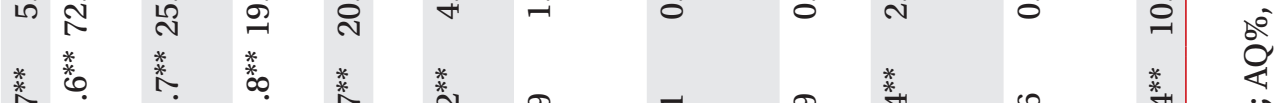

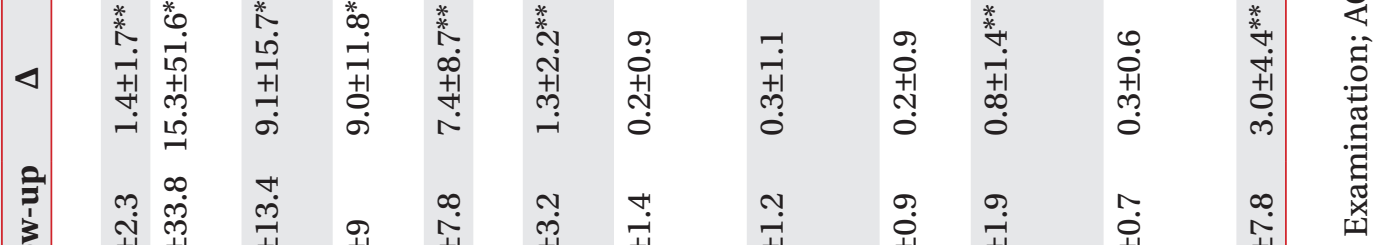

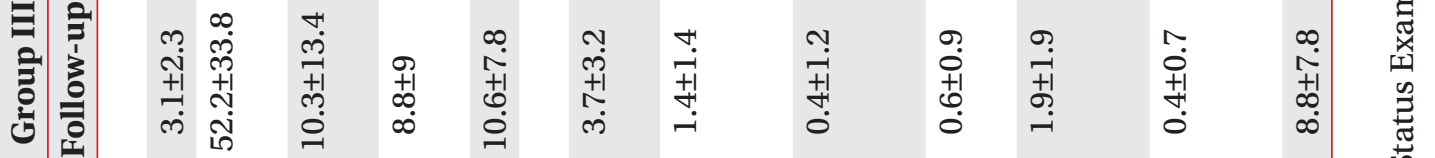

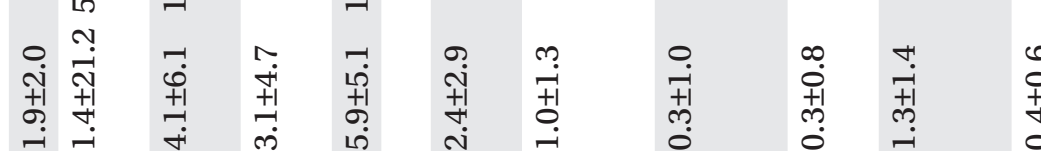

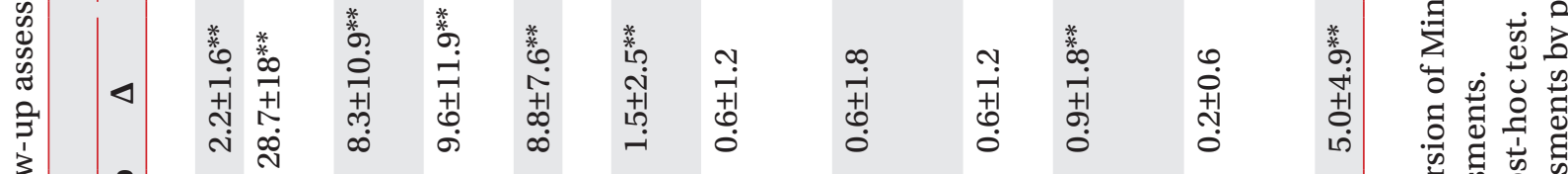

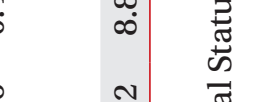

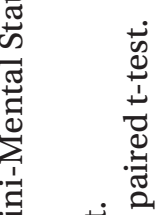

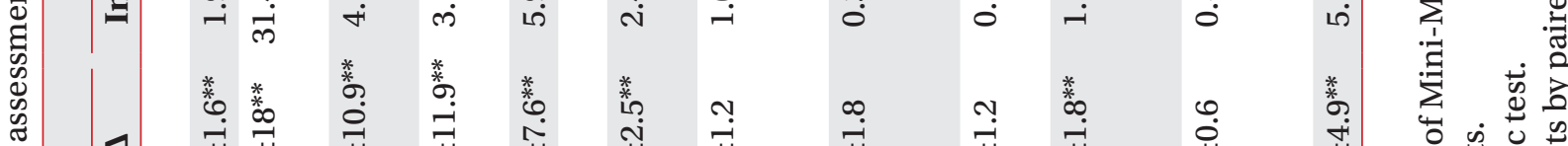

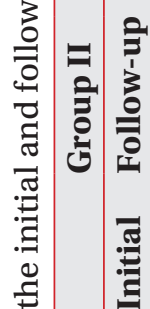

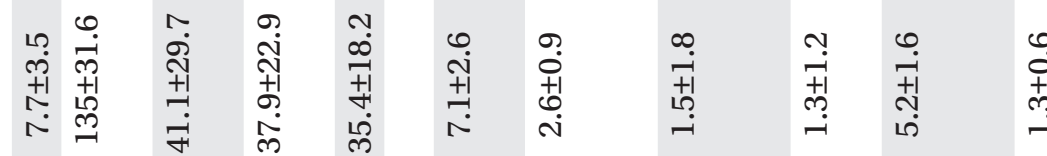

?.1.

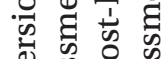

$>$ D

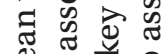

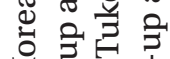

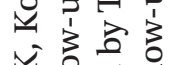

ฺิง

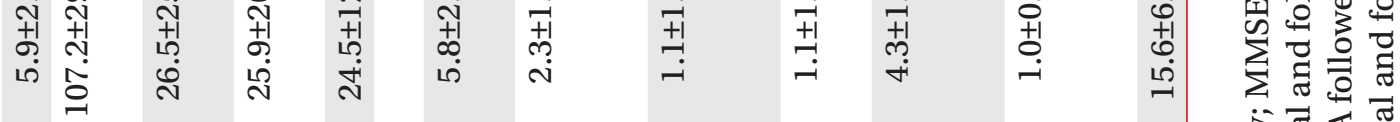

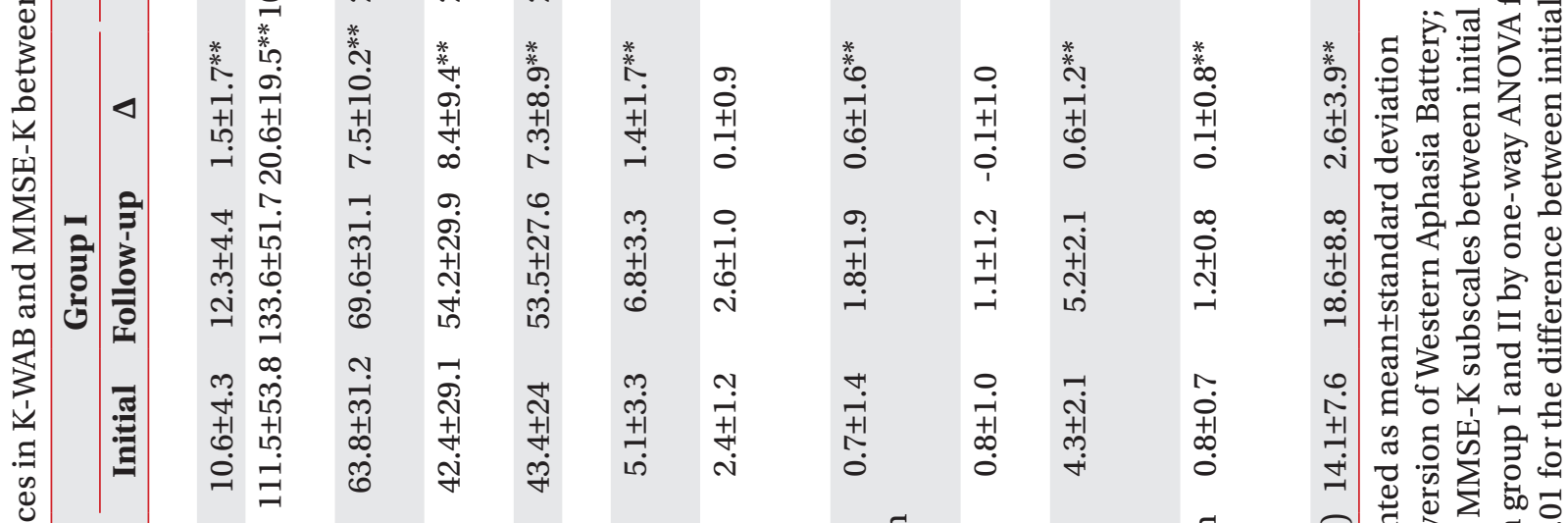

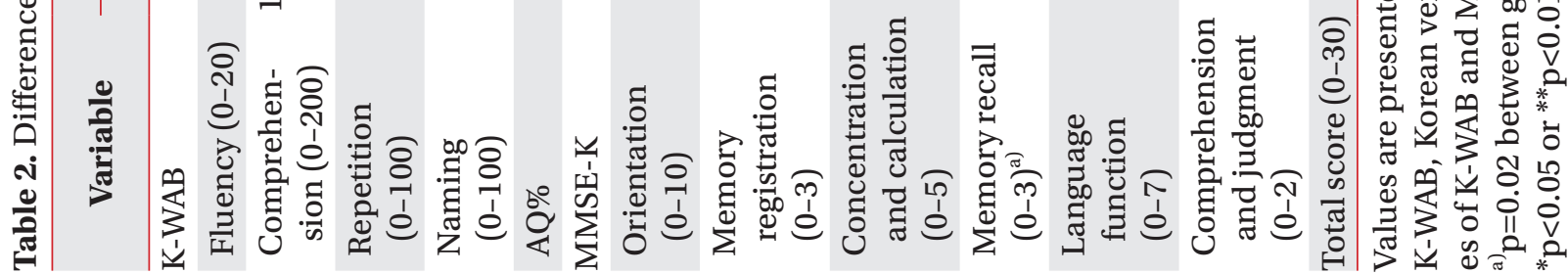


Table 3. Pearson correlation coefficients between differences of K-WAB and MMSE-K, and z-scores showing the differences between two independent correlation coefficients

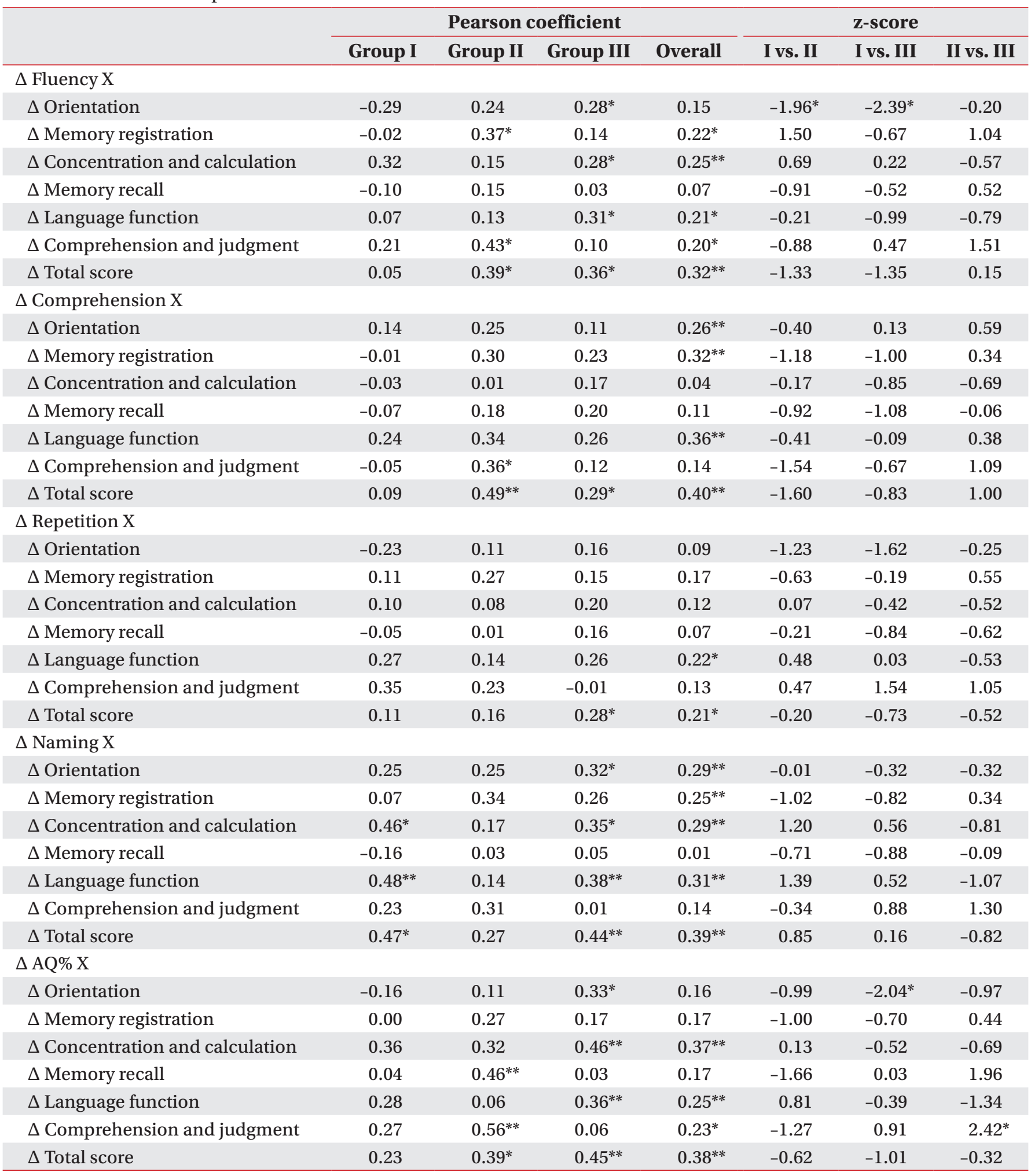

K-WAB, Korean version of Western Aphasia Battery; MMSE-K, Korean version of Mini-Mental Status Examination; $\Delta$, changes of K-WAB and MMSE-K subscales between initial and follow-up assessments; X, pairs between each $\Delta$ of KWAB and MMSE-K subscales.

${ }^{*} \mathrm{p}<0.05$ or ${ }^{* *} \mathrm{p}<0.01$. 
only improved among patients with mild-aphasia (group I; $\mathrm{p}<0.01$ ). A one-way ANOVA followed by Tukey posthoc tests showed that the difference between initial and follow-up assessments of memory recall in group II was greater than group I $(\mathrm{p}=0.02)$.

Table 3 showed the Pearson correlation coefficients between differences in K-WAB and MMSE-K, and z-scores showing the differences between 2 independent correlation coefficients. For group I, there were no significant associations between changes $(\Delta)$ of K-WAB and MMSEK subscales except $\Delta$ naming and both $\Delta$ concentration and calculation $(\mathrm{p}<0.05)$ and $\Delta$ comprehension and judgment $(\mathrm{p}<0.01)$. For group II, $\Delta$ comprehension and judgment was related to $\Delta$ fluency $(\mathrm{p}<0.05), \Delta$ comprehension $(\mathrm{p}<0.05)$, and $\Delta \mathrm{AQ} \%(\mathrm{p}<0.01)$. For group III, the $\Delta$ fluency and $\Delta$ naming subscales and $\triangle \mathrm{AQ} \%$ showed significant correlations with $\Delta$ orientation, $\Delta$ concentration and calculation, and $\Delta$ language function $(\mathrm{p}<0.05$ or $\mathrm{p}<0.01)$. The absolute values of $\mathrm{z}$-scores between group I and III on $\Delta$ orientation of the MMSE- $\mathrm{K}$ and $\Delta$ fluency and $\triangle \mathrm{AQ} \%$ of the K-WAB were $>1.96$ with negative values reflecting more significant correlations in group III. The correlations between $\Delta$ orientation and $\Delta$ fluency, and between $\triangle \mathrm{AQ} \%$ and $\Delta$ comprehension and judgment of group II were greater than those of groups I ( $\mathrm{z}$-score $=-1.96)$ and III ( $\mathrm{z}$-score=2.42).

\section{DISCUSSION}

Stroke is an important cause of functional disability in language, cognition, and physical performance [28]. Language is a part of cognitive processing and is related to other non-linguistic cognitive domains. In the relationship between non-linguistic cognition and language, there is possibly a substantial cognitive contribution to language processing. Impaired syntactic processing is associated with impairments to corresponding non-linguistic cognitive sequential tasks [4,29]. Language processing should be considered alongside cognitive functions, because language processing requires a sequence of receptive stages of dynamic word and phrase recognition and expressive stages of syntactic and semantic structures [30].

Among the post-stroke patients, it is impossible to clarify the categories of language function and other cognitive domains, due to the overlap between language and cog- nitive function. The limited cognitive domains evaluated by non-linguistic neuropsychological tests have shown only weak associations between cognition and language function [13]. Moreover, the difficulty of the neuropsychological tests previously used has prohibited active cognitive assessments for aphasic patients.

MMSE-K has been widely used to assess cognitive functioning. A comprehensive review of the MMSE showed that it can be used as a brief screening test to quantitatively assesses the severity of cognitive impairment and record cognitive changes over time [31]. Moreover, each subscale is can be used to assess an independent cognitive domain $[32,33]$. Thus, in this study we aimed to identify the association between cognition and language function using the easy to adopt MMSE-K, which is regularly used in clinical and research settings. We used the verbal skill assessments of the MMSE-K to indicate language function [34].

Language function outcomes are predicted by initial aphasia severity and other functional outcomes in acute stroke patients [35]; thus, considering the severity of aphasia helps to improve accuracy of determining the association between cognition and language function. We categorized patients into 3 aphasia-cluster groups based on aphasia severity, and compared the results from each group. There were no significant differences in demographic data except age among the 3 groups. Severely impaired aphasia (group III) included global aphasia and moderately impaired aphasia (group II) included Broca's aphasia. Because AQ\% is mainly dependent on fluency score, associations between fluency scores and AQ\% scores might be expected. In this study, all subscores of $\mathrm{K}-\mathrm{WAB}$ were also proportional to the AQ\% of the aphasiacluster groups. Significant improvements across all subscales of K-WAB were observed within each group, but there were no significant differences between the aphasia-cluster groups. Subacute post-stroke aphasic patients (mean post-onset days, 124.6 \pm 80.6 in this study) did not show a correlation between initial aphasia severity and language functional outcome.

In terms of recovery of MMSE-K, the orientation, language function, and total scores improved in each aphasia-cluster group, reflecting that these domains of the MMSE might be explanatory factors for aphasia severity. These results were supported by the fact that orientation is an indicator of general intellectual functions such as 
speech, memory, and attention [36]; in addition, language function of the MMSE-K shares the same cognitive domain as the K-WAB. Moreover, the results of comparisons between correlation coefficients showed that the association of improvement in orientation with that of fluency (group II and III), and improvement in orientation with that of $\mathrm{AQ} \%$ (group II) were superior to group I. Thus, recovery of orientation may contribute to language function in post-stroke patients.

In this study, Pearson correlation coefficients and their comparisons were used to show the definitive association between cognition and language function. In the mildly impaired (group I), only improvement in the naming scale of the K-WAB was related to improvements in cognitive domains such as concentration and calculation, language function, and total score of the MMSE-K. In other aspects, because group I included anomic aphasia, it may reflect the recovery of naming in these patients. Next, in the moderately impaired (group II), improvements in fluency, comprehension, and AQ\% were related to improvements in several cognitive domains such as comprehension and judgment and total score. Additionally, these improvements of comprehension and judgment were also more significantly associated with improvement of $\mathrm{AQ} \%$ in group II, as compared to group III, reflecting the importance of comprehension and judgment in severity of Broca's aphasia, as compared to global aphasia. Finally in the severely impaired (group III), improvements in all subscales of K-WAB showed associations with improvements in more cognitive domains of MMSE- K, as compared to group II. These results indicated that for more severe aphasic conditions, the associations between language function and cognition are stronger.

Besides the evaluated cognitive domains of the MMSE$\mathrm{K}$, there are other cognitive and psychological domains related to language function [6]. For instance, a close relationship may exist between language function and visuospatial perception in post-stroke patients [5], which is not considered in the MMSE-K. Thus, other easy to adopt cognitive tests might be considered to show whether other cognitive influences have a significant effect on language function. Moreover, other factors related to language or cognitive functions such as post-stroke depression [37], medications [38,39] or attendance at language or cognitive rehabilitation programs were not considered in this study; thus, further multidimensional evaluation of post-stroke aphasia patients is required. Additionally, group I showed some inconsistent negative correlations, likely due to inclusion of several kinds of mild aphasia types. However, there were no statistical significances in these values.

This study was the first attempt to show the associations between cognition and language function in subacute post-stroke patients using MMSE-K. The results provided some explanation for the associations. More severely impaired aphasia patients showed a stronger association with cognitive function and recovery of orientation was related to recovery of language function. The MMSE-K can be used as an explanatory tool for predicting severity and recovery of language function in subacute poststroke patients.

\section{CONFLICT OF INTEREST}

No potential conflict of interest relevant to this article was reported.

\section{ACKNOWLEDGMENTS}

This study was supported by 2013 Research Grant from Kangwon National University (No. 120131849).

\section{REFERENCES}

1. Wagle J, Farner L, Flekkoy K, Bruun Wyller T, Sandvik L, Fure B, et al. Early post-stroke cognition in stroke rehabilitation patients predicts functional outcome at 13 months. Dement Geriatr Cogn Disord 2011;31:37987.

2. Sinanovic O, Mrkonjic Z, Zukic S, Vidovic M, Imamovic K. Post-stroke language disorders. Acta Clin Croat 2011;50:79-94.

3. Park JH, Kim BJ, Bae HJ, Lee J, Lee J, Han MK, et al. Impact of post-stroke cognitive impairment with no dementia on health-related quality of life. J Stroke 2013;15:49-56.

4. El Hachioui H, Visch-Brink EG, Lingsma HF, van de Sandt-Koenderman MW, Dippel DW, Koudstaal PJ, et al. Nonlinguistic cognitive impairment in poststroke aphasia: a prospective study. Neurorehabil Neural Repair 2014;28:273-81.

5. Yu ZZ, Jiang SJ, Bi S, Li J, Lei D, Sun LL. Relationship 
between linguistic functions and cognitive functions in a clinical study of Chinese patients with post-stroke aphasia. Chin Med J (Engl) 2013;126:1252-6.

6. Lee B, Pyun SB. Characteristics of cognitive impairment in patients with post-stroke aphasia. Ann Rehabil Med 2014;38:759-65.

7. Kwon JY, Kim JS, Park SW, Jang SJ, Kim BS. Influence of aphasia on the cognitive screening test in stroke patients with unilateral cerebral hemispheric lesion. J Korean Acad Rehabil Med 2002;26:9-13.

8. Rice ML. Contemporary accounts of the cognition/ language relationship: implications for speech-language clinicians. J Speech Hear Disord 1983;48:34759.

9. Tatemichi TK, Desmond DW, Stern Y, Paik M, Sano M, Bagiella E. Cognitive impairment after stroke: frequency, patterns, and relationship to functional abilities. J Neurol Neurosurg Psychiatry 1994;57:202-7.

10. Katz N, Itzkovich M, Averbuch S, Elazar B. Loewenstein Occupational Therapy Cognitive Assessment (LOTCA) battery for brain-injured patients: reliability and validity. Am J Occup Ther 1989;43:184-92.

11. Pedersen PM, Jorgensen HS, Nakayama H, Raaschou HO, Olsen TS. Aphasia in acute stroke: incidence, determinants, and recovery. Ann Neurol 1995;38:659-66.

12. Lazar RM, Minzer B, Antoniello D, Festa JR, Krakauer JW, Marshall RS. Improvement in aphasia scores after stroke is well predicted by initial severity. Stroke 2010;41:1485-8.

13. Raven J. Raven progressive matrices. In: McCallum RS, editor. Handbook of nonverbal assessment. New York: Kluwer Academic/Plenum Publishers; 2003. p. 223-37.

14. Helm-Estabrooks N. Cognition and aphasia: a discussion and a study. J Commun Disord 2002;35:171-86.

15. Kwon YC, Park JH. Korean version of Mini-Mental State Examination (MMSE-K). Part I: development of the test for the elderly. J Korean Neuropsychiatr Assoc 1989;28:125-35.

16. Park JH, Kwon YC. Standardization of Korean version of the Mini-Mental State Examination (MMSE-K) for use in the elderly. Part II: diagnostic validity. J Korean Neuropsychiatr Assoc 1989;28:508-13.

17. Guerrero-Berroa E, Luo X, Schmeidler J, Rapp MA, Dahlman K, Grossman HT, et al. The MMSE orientation for time domain is a strong predictor of subse- quent cognitive decline in the elderly. Int J Geriatr Psychiatry 2009;24:1429-37.

18. Kim H, Na DL. Paradise-Korean version of the Western Aphasia Battery. Seoul: Paradise Welfare Foundation; 2001.

19. Kertesz A, Poole E. The aphasia quotient: the taxonomic approach to measurement of aphasic disability. Can J Neurol Sci 1974;1:7-16.

20. Kertesz A. Aphasia and associated disorders: taxonomy, localization, and recovery. New York: Grune \& Stratton; 1979.

21. Katz N, Elazar B, Itzkovich M. Construct validity of a geriatric version of the Loewenstein Occupational Therapy Cognitive Assessment (LOTCA) battery. Phys Occup Ther Geriatr 1995;13:31-46.

22. Katz N, Hartman-Maeir A, Ring H, Soroker N. Relationships of cognitive performance and daily function of clients following right hemisphere stroke: predictive and ecological validity of the LOTCA battery. OTJR (Thorofare N J) 2000;20:3-17.

23. Folstein MF, Folstein SE, McHugh PR. "Mini-mental state": a practical method for grading the cognitive state of patients for the clinician. J Psychiatr Res 1975;12:189-98.

24. Oldfield RC. The assessment and analysis of handedness: the Edinburgh inventory. Neuropsychologia 1971;9:97-113.

25. Martinez IN, Moran JM, Pena FJ. Two-step cluster procedure after principal component analysis identifies sperm subpopulations in canine ejaculates and its relation to cryoresistance. J Androl 2006;27:596-603.

26. Preacher KJ. Calculation for the test of the difference between two independent correlation coefficients [Internet]. [place unknown: publisher unknown]; 2002 [cited 2016 Jan 15]. Available from: http://www. quantpsy.org/corrtest/corrtest.htm.

27. Cohen J, Cohen P, West SG, Aiken LS. Applied multiple regression/correlation analysis for the behavioral sciences. 3rd ed. Hoboken: Taylor and Francis; 2013.

28. Kalaria RN, Ballard C. Stroke and cognition. Curr Atheroscler Rep 2001;3:334-9.

29. Dominey PF, Hoen M, Blanc JM, Lelekov-Boissard T. Neurological basis of language and sequential cognition: evidence from simulation, aphasia, and ERP studies. Brain Lang 2003;86:207-25.

30. Massaro DW. Understanding language: an informa- 
tion-processing analysis of speech perception, reading, and psycholinguistics. New York: Academic Press; 1975.

31. Tombaugh TN, McIntyre NJ. The mini-mental state examination: a comprehensive review. J Am Geriatr Soc 1992;40:922-35.

32. Schultz-Larsen K, Kreiner S, Lomholt RK. MiniMental Status Examination: mixed Rasch model item analysis derived two different cognitive dimensions of the MMSE. J Clin Epidemiol 2007;60:268-79.

33. Lee HJ, Choi HY, Yun KW, Kim YC, Lim WJ, Kim JH, et al. Association between Obesity Indices and MMSE-K in elderly. J Korean Neuropsychiatr Assoc 2013;52:44753.

34. Feher EP, Mahurin RK, Doody RS, Cooke N, Sims J, Pirozzolo FJ. Establishing the limits of the Mini-Mental State. Examination of 'subtests'. Arch Neurol 1992; 49:87-92.
35. Pedersen PM, Vinter K, Olsen TS. Aphasia after stroke: type, severity and prognosis: the Copenhagen aphasia study. Cerebrovasc Dis 2004;17:35-43.

36. Pedersen PM, Jorgensen HS, Nakayama H, Raaschou HO, Olsen TS. Orientation in the acute and chronic stroke patient: impact on ADL and social activities. The Copenhagen Stroke Study. Arch Phys Med Rehabil 1996;77:336-9.

37. Sinyor D, Amato P, Kaloupek DG, Becker R, Goldenberg M, Coopersmith H. Post-stroke depression: relationships to functional impairment, coping strategies, and rehabilitation outcome. Stroke 1986;17:1102-7.

38. Berthier ML, Green C, Higueras C, Fernandez I, Hinojosa J, Martin MC. A randomized, placebo-controlled study of donepezil in poststroke aphasia. Neurology 2006;67:1687-9.

39. Wong IC, Lhatoo SD. Adverse reactions to new anticonvulsant drugs. Drug Saf 2000;23:35-56. 